This item was submitted to Loughborough's Research Repository by the author.

Items in Figshare are protected by copyright, with all rights reserved, unless otherwise indicated.

\title{
Computational analysis of fibre bonding in the through-air process
}

PLEASE CITE THE PUBLISHED VERSION

PUBLISHER

Professional Engineering Publishing / @ IMechE

VERSION

VoR (Version of Record)

LICENCE

CC BY-NC-ND 4.0

REPOSITORY RECORD

Hossain, Mamdud, Memis Acar, and W. Malalasekera. 2019. "Computational Analysis of Fibre Bonding in the Through-air Process". figshare. https://hdl.handle.net/2134/4525. 
This item was submitted to Loughborough's Institutional Repository (https://dspace.lboro.ac.uk/) by the author and is made available under the following Creative Commons Licence conditions.

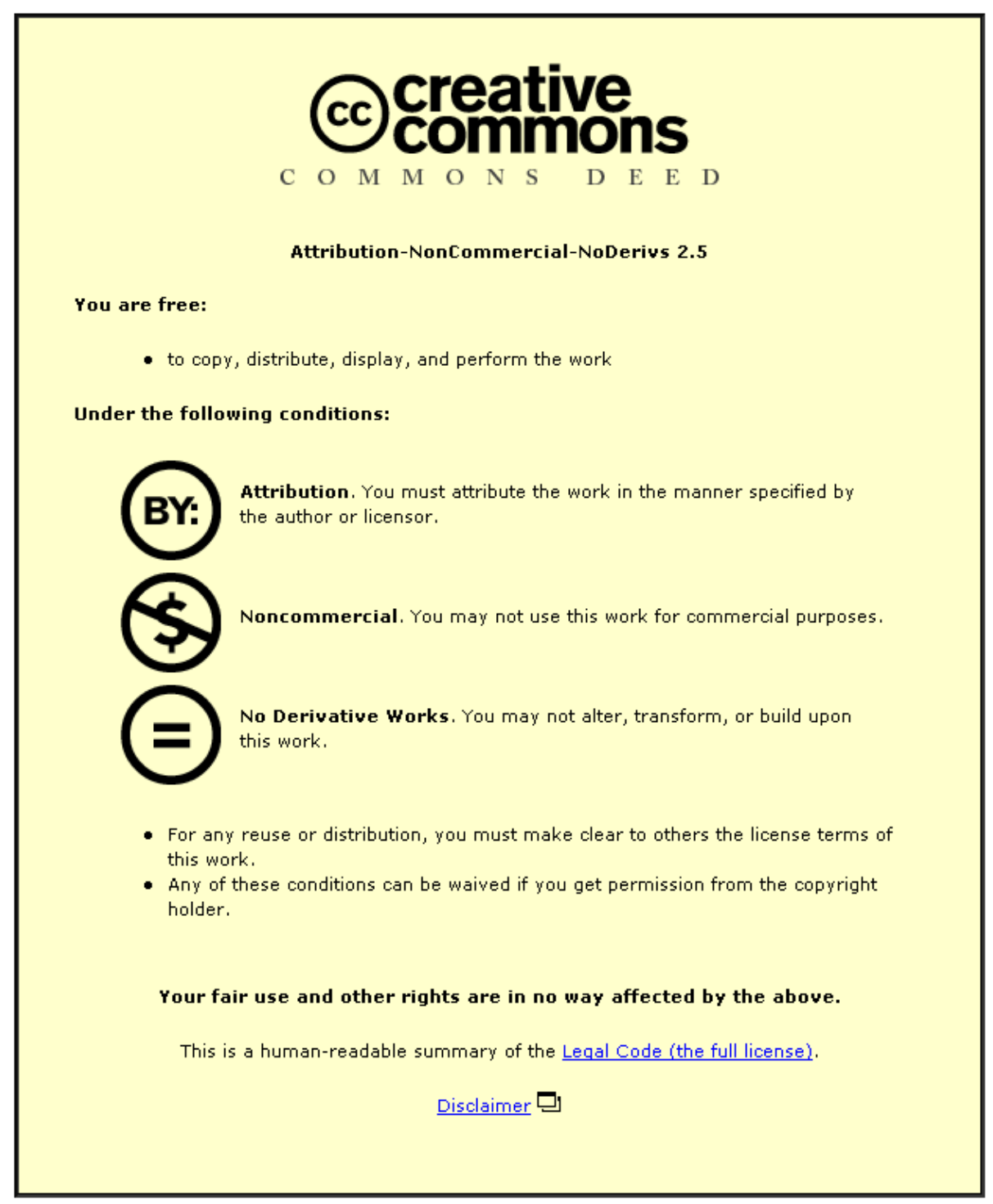

For the full text of this licence, please go to: http://creativecommons.org/licenses/by-nc-nd/2.5/ 


\title{
Computational analysis of fibre bonding in the through-air process
}

\author{
M Hossain $^{1 *}$, M Acar ${ }^{2}$, and W Malalasekera ${ }^{2}$ \\ ${ }^{1}$ School of Engineering, The Robert Gordon University, Aberdeen, UK \\ ${ }^{2}$ Department of Mechanical and Manufacturing Engineering, Loughborough University, Leicestershire, UK
}

The manuscript was received on 5 June 2006 and was accepted after revision for publication on 19 October 2006.

DOI: 10.1243/0954408JPME104

\begin{abstract}
Through-air bonding is one of the thermal methods of bonding fibres in the production of non-woven webs. A computational study of the formation of bond point between two bicomponent fibres during the through-air bonding process is reported in this paper. The computational method involves solving the Navier-Stokes equations for two-phase flows of air and molten polymer in a three-dimensional configuration. The heating, melting, and bonding of fibres are modelled by the volume of fluid model together with a melting model. The simulated results show the formation of the bond between two fibres in contact and the change of shape of the bond with time at different bonding temperatures. The computation shows that the rate of bonding increases slightly at higher temperature.
\end{abstract}

Keywords: non-wovens, through-air bonding, computational fluid dynamics

\section{INTRODUCTION}

Bicomponent fibres consisting of core and sheath polymers of two different melting points are widely used in the through-air bonding process (passing hot air through a web of fibres) to produce bonded non-woven webs. The mechanical properties such as tensile strength, tear strength, and bending properties of non-woven webs largely depend on the degree of bonding. Therefore, the bonding process is the most important factor for controlling the mechanical properties of the non-woven webs. A better understanding of the formation of bond is essential for the improvement of the existing products and processes, cost savings, and the development of new products. The through-air bonding process involves passing hot air through an unbonded non-woven web, usually wrapped around a perforated rotating drum and heating the fibres above melting temperature of sheath fibre, which melts and flows towards the crossover point of the two adjacent fibres in contact to form

\footnotetext{
${ }^{*}$ Corresponding author: School of Engineering, The Robert Gordon University, Schoolhill, Aberdeen, Aberdeenshire AB10 1FR, UK. email:m.hossain@rgu.ac.uk
}

a bond. However, it is recognized that the optimum heating and bonding conditions for the through-air bonding is difficult to establish. The non-woven fabrics will be weak if there is insufficient bonding, on the other hand, the fibres will melt and deform if excessive heat is applied. One way to establish the optimum bonding condition is by experimentation under different conditions in a production line. However, this process is time consuming, expensive, and often not profitable. Mukhopadhyay et al. [1] proposed a single-fibre test method that can provide a better insight into the thermal bonding behaviour than measuring the non-woven fabrics from full-scale production lines. Kim et al. [2] reported an experimental investigation of thermal-bonding behaviour of two bicomponent fibres in point contact under different bonding temperatures and fibre diameters. Subsequently, Kim et al. [3] reported a numerical investigation for the same experimental set-up and represented the three-dimensional fibre configuration by two cases of two-dimensional flow: first case representing the flow along the fibre axis and the second case representing the flow perpendicular to the fibre axis. Although their simulation reproduced a general trend of the bonding point, it failed to represent the three-dimensional nature of the shape of the bond point. 


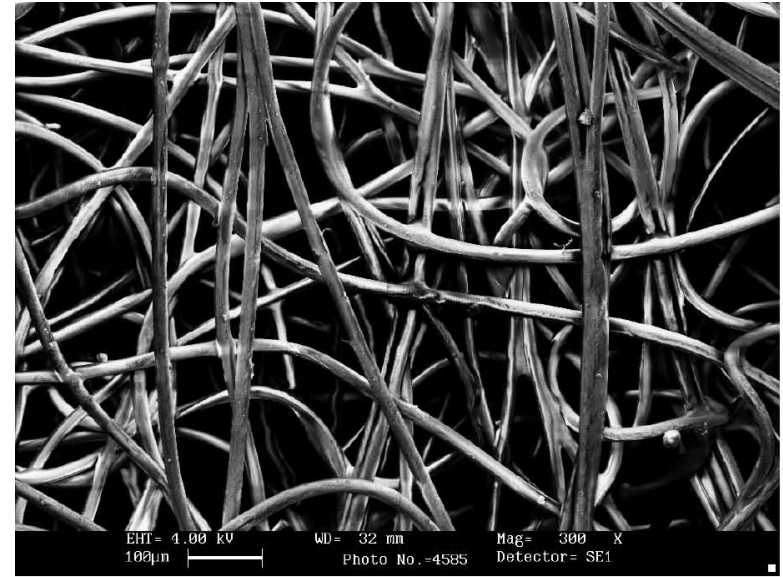

(a)

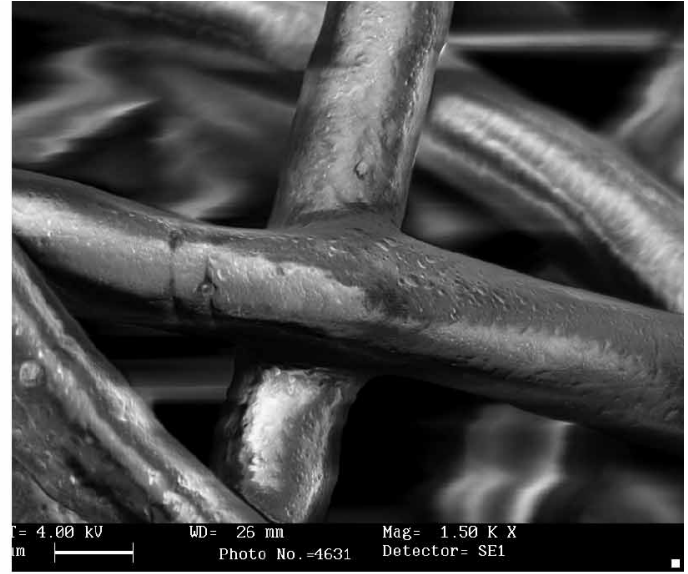

(b)

Fig. 1 Scanning electron micrograph of (a) a through-air bonded non-woven web and (b) a bond point between two fibres laying perpendicularly

In an earlier study, Hossain et al. [4] investigated the airflow and heat transfer through a non-woven web treating the web as a porous media in macroscale. The research work investigated the time of heating of the web under different operating conditions. In the present study, the airflow and heat transfer, melting, and bonding of fibres are analysed in microscale by the computational fluid dynamics (CFD) technique. The computational technique involves modelling of melting of fibres and two-phase flow modelling of air and molten polymer using the volume of fluid (VOF) method. Figure 1(a) shows a scanning electron micrograph of a through-air bonded non-woven web. Because of the statistical nature of fibre distribution in a web, it is very difficult and resources intensive to generate a realistic computational model for a complete web. However, the analysis of the formation of a single bond point will provide an insight into the bonding behaviour. Therefore, a single bond modelling strategy is adapted to investigate the formation of a bond between two fibres laying perpendicular to each other similar to the one shown in Fig. 1(b).

\section{MODELLING APPROACH}

\subsection{Mathematical formulation}

The two-phase VOF method is used for the modelling of the air and molten polymer fibre flows. In the VOF method, a single set of momentum equations is shared by phases (here, air, and polymer), and volume fraction of each phase is tracked through the computational domain. The solidification/melting model is also utilized to model the melting of fibres. The surface tension force plays the most important role in the bond forming process and therefore is included in the computational model. The governing equations for the VOF model are given below.

Continuity

$$
\frac{\partial \rho}{\partial t}+\nabla \cdot(\rho \bar{u})=0
$$

\section{Momentum}

$$
\begin{aligned}
& \frac{\partial(\rho \bar{u})}{\partial t}+\nabla \cdot(\rho \bar{u} \bar{u}) \\
& \quad=-\nabla P+\nabla \cdot \mu\left(\nabla \bar{u}+\nabla \bar{u}^{\mathrm{T}}\right)+S+F
\end{aligned}
$$

Initially, the fibres are in solid state and obviously the velocity is zero. When the fibres are melted by heat transfer from the flowing hot air, the molten polymer starts to flow. The term $S$ in the above works as a momentum sink to ensure that the fibre velocities in the initial cold state and then in the molten hot state are correctly represented. The surface tension force in equation (2) is represented by $F$. The force at the surface is expressed as a volume force and is added to the momentum equation as a source term.

Energy equation

$$
\frac{\partial}{\partial t}(\rho H)+\nabla \cdot(\rho \bar{u} H)=\nabla \cdot\left(k_{\mathrm{eff}} \nabla T\right)+S_{\mathrm{h}}
$$

where $S_{\mathrm{h}}$ is a source term in the energy equation. This term represent the thermal energy needed to melt fibres.

Volume fraction equation

To track the interface between phases a volume fraction continuity equation for the secondary phase (fibre) is solved along with the above equations

$$
\frac{\partial \alpha_{q}}{\partial t}+\vec{u} \cdot \nabla \alpha_{q}=0
$$

where subscript $q$ represents each phase component. Air volume fraction is obtained from the relation 
$\sum_{q=1}^{2} \alpha_{q}=1$. The properties appearing in the transport equations are determined by the presence of the component phases in each control volume. For example, the density is considered to be

$$
\rho=\sum_{q=1}^{2} \alpha_{q} \rho_{q}
$$

\subsection{Parameters for computation}

The fibre used for the computation study is a polyethylene (PE) sheath and polypropylene (PP) core bicomponent fibre. The sheath diameter is $15.15 \mu \mathrm{m}$ and the core diameter is $10.86 \mu \mathrm{m}$. The bonding is investigated at temperatures of 130,140 , and $150^{\circ} \mathrm{C}$. The viscosity of the sheath polymer at $140^{\circ} \mathrm{C}$ is experimentally measured to be $600 \mathrm{Pas}$ [3]. The viscosity at $130^{\circ} \mathrm{C}$ and $150^{\circ} \mathrm{C}$ was calculated to be 745 and $488 \mathrm{~Pa}$ s, respectively, from the Arrhenius equation

$$
\frac{\mu}{\mu_{\mathrm{o}}}=\exp \left(\frac{E_{\mathrm{a}}}{R}\left(\frac{1}{T}-\frac{1}{T_{\mathrm{o}}}\right)\right)
$$

where, $E_{\mathrm{a}}$ is the activation energy of $30 \mathrm{~kJ} / \mathrm{mol}, R$ is the universal gas constant.

The surface tension is calculated using the equation

$$
\sigma=\sigma_{\mathrm{c}}\left(1-T / T_{c}\right)^{11 / 9}
$$

where $\sigma$ and $\sigma_{\mathrm{c}}$ are the surface tension at temperatures $T$ and the critical temperature $T_{\mathrm{c}}$, respectively. With the critical temperature of $1000 \mathrm{~K}$ and the surface tension of $26.6 \mathrm{mN} / \mathrm{m}$ at $150^{\circ} \mathrm{C}$ [3], the values of surface tension at 140 and $130^{\circ} \mathrm{C}$ were calculated to be 27.1 and $27.7 \mathrm{mN} / \mathrm{m}$. The density of the PE is taken as $900 \mathrm{~kg} / \mathrm{m}^{3}$ and that of PP as $950 \mathrm{~kg} / \mathrm{m}^{3}$. The values of specific heat are set at 1800 and $1600 \mathrm{~J} / \mathrm{kg} \mathrm{K}$ for PE and PP, respectively. The thermal conductivities of PE and $\mathrm{PP}$ are 0.35 and $0.2 \mathrm{~W} / \mathrm{mK}$, respectively. The heat of melting of PE polymer is set at $3.52 \mathrm{~kJ} / \mathrm{mol}$. The values of density, specific heat, thermal conductivity, and heat of melting of PE are supplied by fibre manufacturer KoSa.

\subsection{Computation methodology}

A commercial CFD software Fluent is used for the reported computational work [5]. The underlying methodology of Fluent finite volume software is to divide the computational domain into a number of control volumes. The governing partial differential equations are then converted, by integration over these control volumes, into their equivalent algebraic equations. A second order upwind scheme [6] is used for discretization of the governing differential equations. The resulting algebraic equations are solved in an iterative fashion using pressure-implicit with splitting of operators (PISO) method [7], with a time step

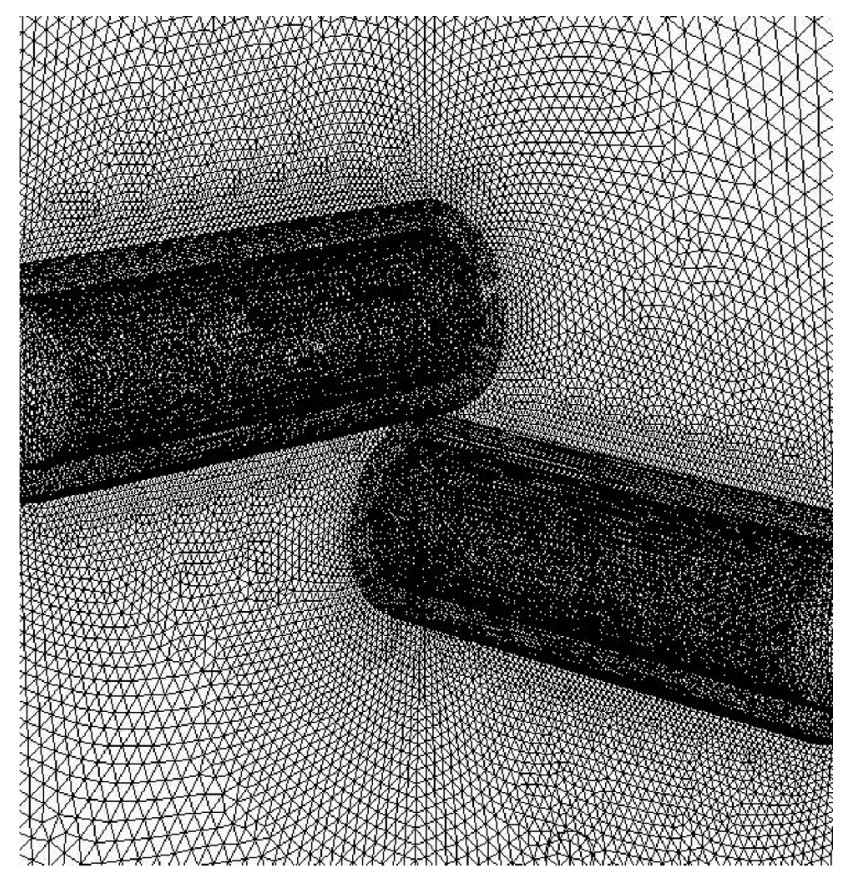

Fig. 2 Computational grid around the contact point of two fibres

of $10^{-6} \mathrm{~s}$. The computational domain is made of $\sim 1.3$ millions tetrahedral cells, which provided a grid independent solution. This grid arrangement, shown in Fig. 2, remained fixed during the solution process.

The computational modelling of the present study also requires modelling of melting in conjunction with modelling two-phase flows. The Fluent software employs an enthalpy-porosity $[\mathbf{8}]$ method for the modelling of the melting of solid. In this technique, a liquid fraction is defined to identify the melting of solid in each cell. The liquid fraction is computed at each iteration based on an enthalpy balance. The value of liquid fraction of one indicates the material is in liquid from and the flow of the molten material is then described by the VOF model [9]. The Euler explicit scheme was used to trace the air-PE interface during each iteration. The heat transfer between air and fibres are modelled using conjugate heat transfer concept in that density and thermal conductivity is shared by the phases. This method is simple to implement in the computational process [5].

\section{RESULTS AND DISCUSSION}

The application of the computational fluid dynamics technique reveals a number of flow features. A selection of flow field and temperature obtained from the computation are described below.

\subsection{Heating}

In the though-air bonding process, the fibres are heated, softened, and melted by flowing hot air. The 
simulated results of heating to melting of fibres are shown in Figs 3-5. The complex flow pattern of air over the fibres is shown in Fig. 3. Figure 4 shows the progression of heating of fibres. Hot air at a temperature of $413 \mathrm{~K}\left(140^{\circ} \mathrm{C}\right)$ and at a velocity of $1.5 \mathrm{~m} / \mathrm{s}$ is passed over the fibres. The heat is convected from the air to the fibre surface and then conducted through the fibre. When the fibre temperature exceeds the melting temperature of $128^{\circ} \mathrm{C}$, the PE sheath starts to melt. The melt fraction of fibres is shown in Fig. 5. It took $\sim 6.5 \mathrm{~ms}$ to heat the fibres to melting temperature. The heating and melting times are influenced by the air temperature. At air temperature of $130^{\circ} \mathrm{C}$ the computed heating time is $15 \mathrm{~ms}$, at $150^{\circ} \mathrm{C}$, the heating time is $4 \mathrm{~ms}$.

\subsection{Bonding}

A typical bonding behaviour of the two PE sheath/PP core bicomponent fibres is shown in Figs 6 and 7 . Figure 6 shows the velocity vector of the molten PE flow. At the initial stage, the velocity near the contact point is relatively high. The molten polymer flows quickly to the contact point to fill up the gap. As the gap fills up, the velocity decreases and the polymer further away from the contact point starts to flow towards the bond. Figure 6 shows the threedimensional shape of the formation of bond at different dwell time. The bonding starts at the intersection of two fibres. The flow of molten PE proceeds to form a bond at the intersection to minimize the surface energy, in that the polymer flows towards the contact point by surface tension force. In the initial stage

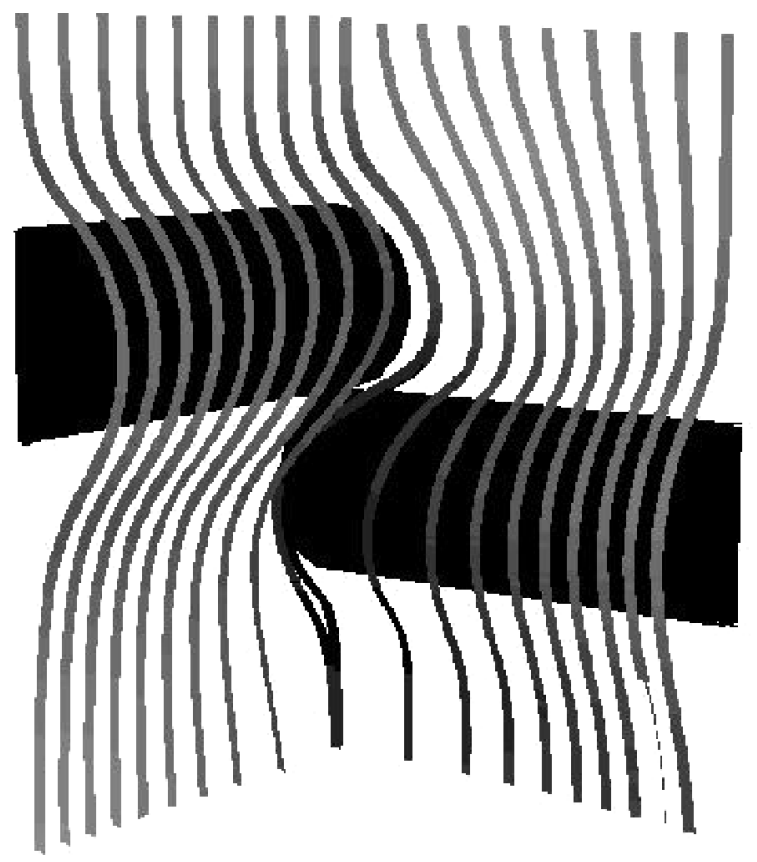

Fig. 3 Computed pathlines of airflow over the fibres

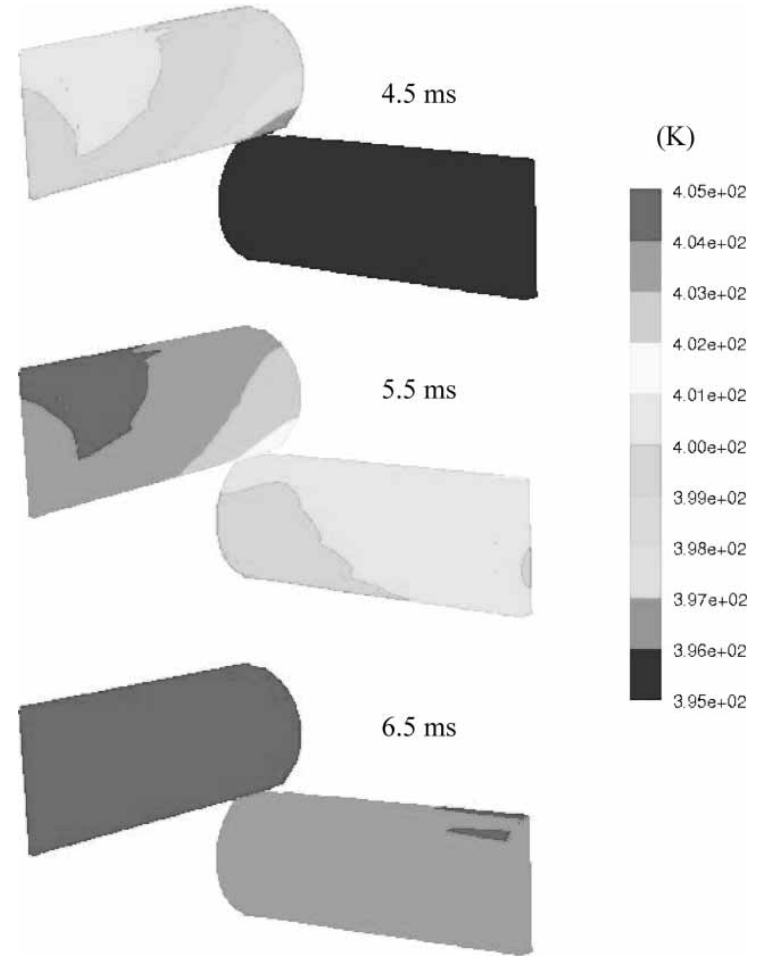

Fig. 4 Temperature of fibres at different time steps for bonding temperature of $140^{\circ} \mathrm{C}$
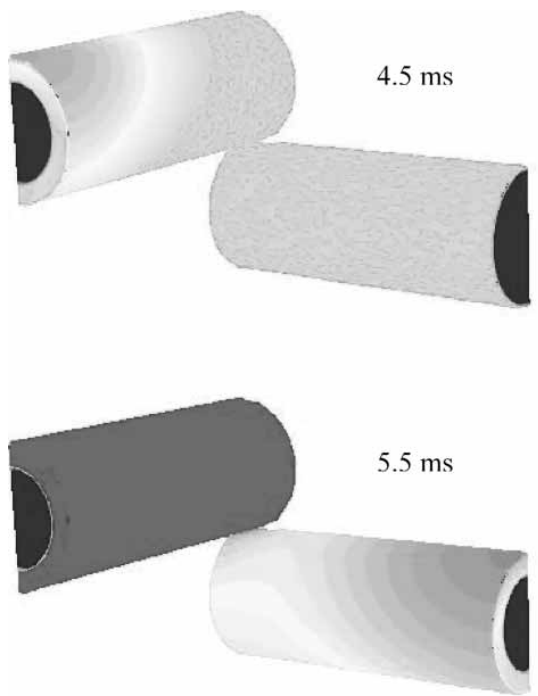
$9.00 \mathrm{e}-01$ $8.50 \mathrm{e}-01$ $8.00 \mathrm{e}-01$ $750 \mathrm{e}-01$ $7.00 \mathrm{e}-01$ $6.50 \mathrm{e}-01$ $6.00 \mathrm{e}-01$ $5.50 \mathrm{e}-01$ $5000-01$ 5.00e-01 $4.50 \mathrm{e}-01$ $3.50 \mathrm{e}-01$ $3.00 \mathrm{e}-01$ 25001 $2.00 \mathrm{e}-01$
$1.50 \mathrm{e}-01$ $1.00 \mathrm{e}-01$ $5.00 \mathrm{e}-02$

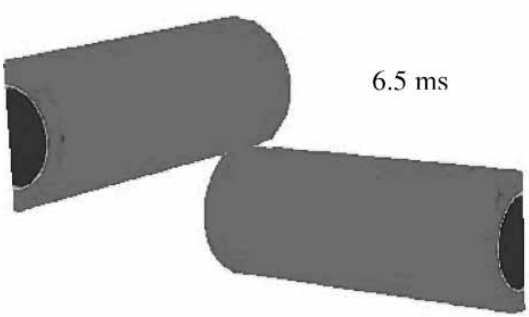

Fig. 5 Progression of melting of fibres heated by hot air at $140{ }^{\circ} \mathrm{C}$ 


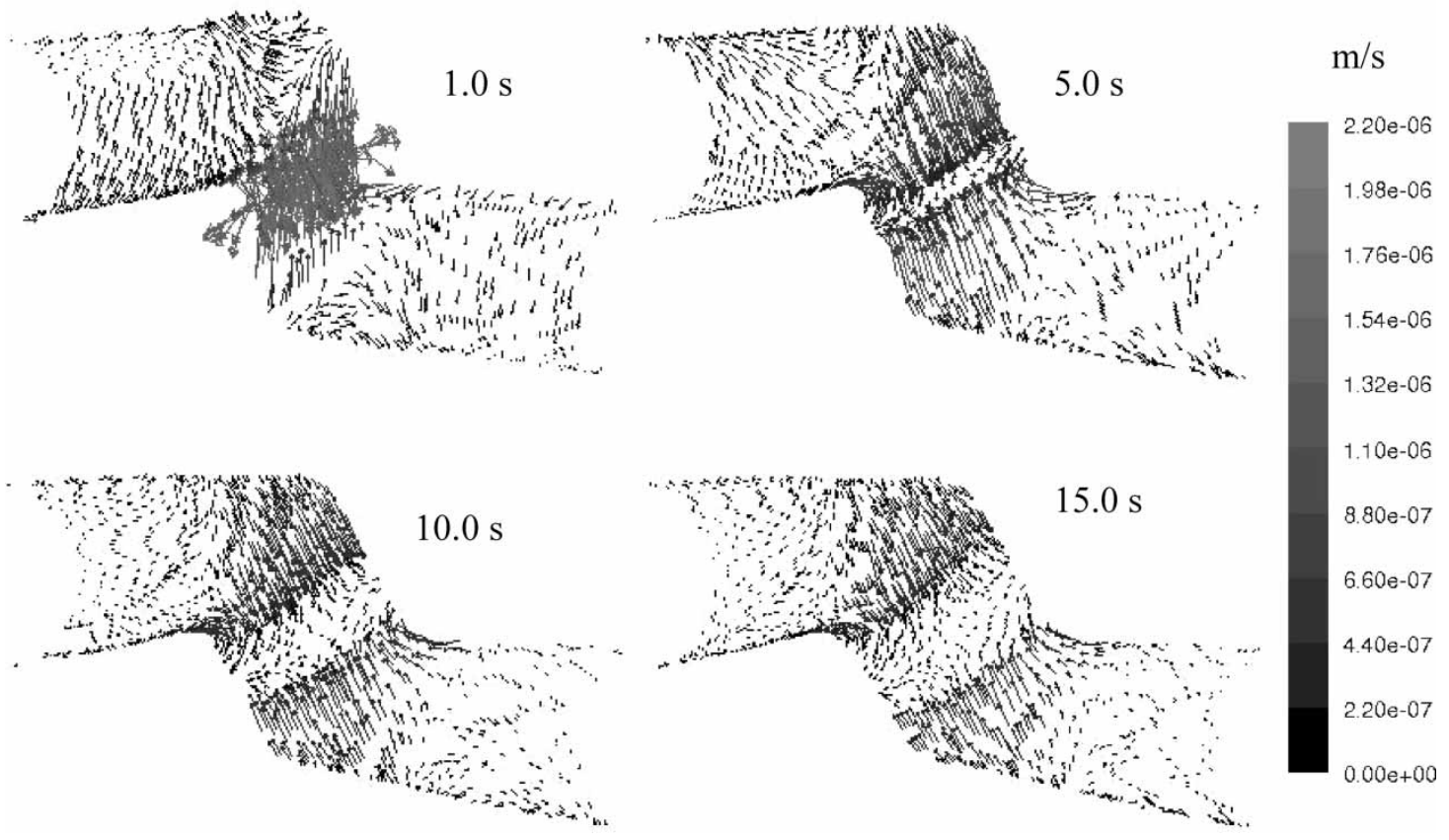

Fig. 6 Velocity vector of molten polymer at different time steps for a bonding temperature of $140{ }^{\circ} \mathrm{C}$

of bonding, the sheath PE flows circumferentially to the contact point, and then the polymer flows along the fibre axis towards the bond point. Accordingly, the thickness of the sheath polymer in the vicinity of the intersection begins to decrease. With the increase in the bonding time, the amount of sheath polymer at the intersection continues to increase and the fibre diameter in the vicinity of the intersection continues to decrease.

In order to characterize the features of the bonding process, a characteristic bond size is defined as the diameter of the section of the bond on the horizontal plane through the contact point as shown in Fig. 8. Figure 9 shows the changes of the bonding size with bonding time under different bonding temperatures. A dimensionless bond size is defined
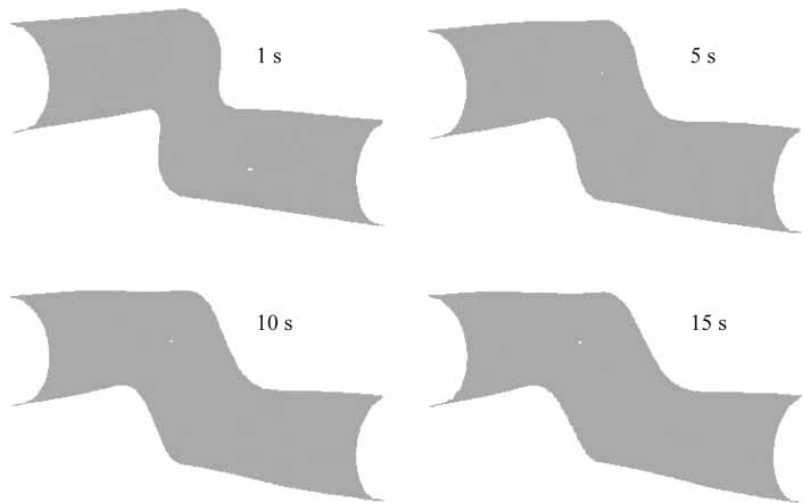

Fig. 7 Formation of bond with increasing time calculated for the bonding temperature of $140^{\circ} \mathrm{C}$

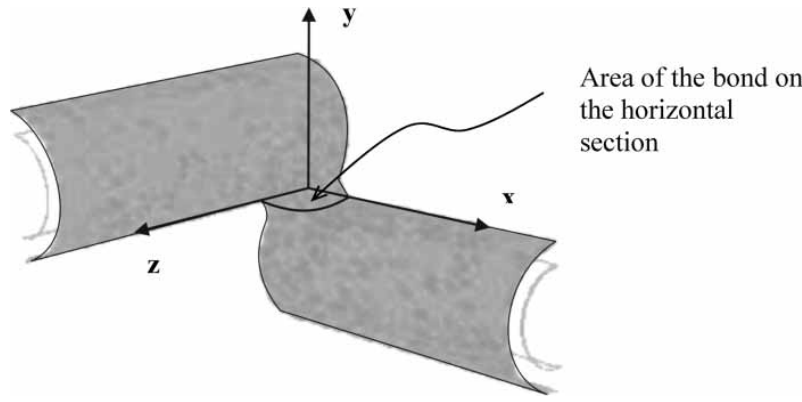

Fig. 8 Characteristic bond area on the horizontal plane. The size of the bond is characterized by the diameter of this area

by dividing the bond diameter by the initial fibrediameter $D_{\mathrm{o}}$. The bonding proceeds at a faster rate at the initial stages of bonding. The molten polymer flows rapidly to fill up the narrow gap at the contact point of two fibres. As the gap is filled up, the bonding proceeds at a slower rate (Fig. 9) and the bond size curve becomes almost linear after $4-5 \mathrm{~s}$, with a low gradient. The effect of temperature on the rate of bonding is also shown in the same figure. The bonding proceeds at a slightly faster rate at higher temperature. Surface tension and viscosity are the two most important parameters that control the flow of the molten polymer. When the bonding temperature changes from $130^{\circ} \mathrm{C}$ to $150^{\circ} \mathrm{C}$ the viscosity and surface tension force decreases by about 65.5 and 96 per cent, respectively. At higher temperatures, the surface tension force, which is the driving force for the formation of the bond, decreases which leads to a slower rate of bonding. On the other hand, the reduction 


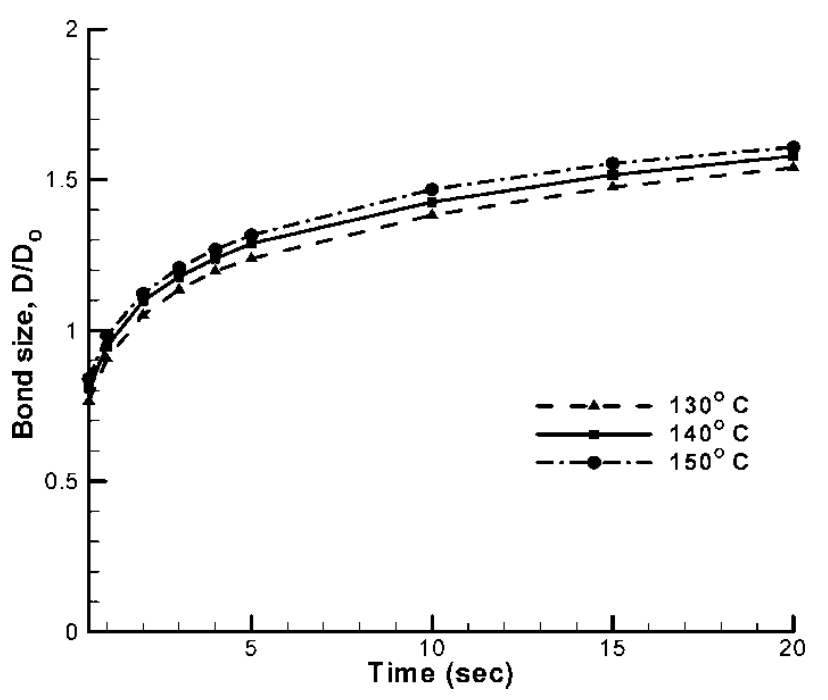

Fig. 9 Change of bond size evaluated from the simulated results as a function of bonding time for three different bonding temperatures

of the viscosity at the higher temperatures leads to a faster rate of bonding. Overall, the reduction of the viscosity at higher temperatures more than compensate the reduction of the surface tension force and this leads to a small increase of the bonding rate at higher temperatures.

The effect of fibre diameter on the bonding time is also computed using fibres diameter of 21.6, 25.1, and $30.3 \mu \mathrm{m}$. The changes of the bonding size for different fibre diameters are plotted in Fig. 10. This figure shows that the time needed to form bond increases with the increase of fibre diameter. This seems natural because the absolute rate of polymer flow induced by the surface tension force depends only on the curvature of

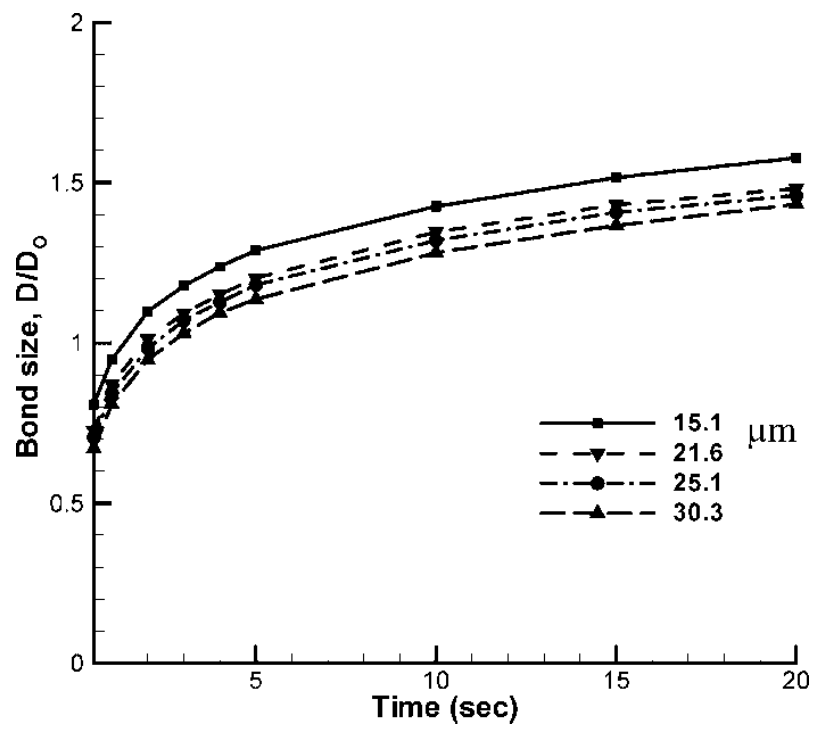

Fig. 10 Change of bond size evaluated from the simulated results as a function of bonding time for three different fibre diameters polymer surface at the contact point of two fibres. The surface curvature at the contact point of fibres with smaller diameters is sharper, which results in higher surface tension force and the faster bonding rate compared to larger diameters. Similar observations were also made experimentally by Kim et al. [2].

\section{CONCLUSIONS}

Through-air bonding of two fibres in a threedimensional configuration is numerically simulated by using a VOF model. The computation shows that the heating time is greatly influenced by the air temperature; however, compared to the bonding time, it is two/three orders of magnitude shorter. The bonding starts at a faster pace with the flowing of the sheath material to fill up the gap in the contact point of two fibres. Then the bonding process proceeds more slowly. The time required for the formation of bond is investigated under different bonding temperatures. The bonding proceeds faster at higher temperatures mainly because of the reduction of the polymer viscosity. However, the effect of temperature on the formation of bond appears to be small. The effect of bonding size on the fibre diameter is also studied. The bonding time increases with the increase of fibre diameter.

\section{ACKNOWLEDGEMENTS}

The research work is financially supported by Nonwovens Cooperative Research Center, Raleigh, NC, USA. We gratefully acknowledge their support. We also acknowledge the support of fibre manufacturer KoSa for providing fibre specifications.

\section{REFERENCES}

1 Mukhopadhyay, S. K., Hearle, J. W. S., and Foster, P. W. A new test method for studying the thermal bonding behaviour studying synthetic fibres. J. Text. Inst., 1988, 79, 235-241.

2 Kim, H. S., Ito, H., Kikutani, T., and Okui, N. The thermal bonding behaviour of polyethylene/polyethylene terephthalate bicomponent fibres. J. Text. Inst., 1997, 88, (pt 3), $37-51$.

3 Kim, H. S., Ito, H., Kikutani, T., and Okui, N. Computational analysis on the thermal bonding behaviour of bicomponenet fibres. J. Text. Inst., 1999, 90(4), 508-525.

4 Hossain, M., Acar, M., and Malalasekera, W. A mathematical model for airflow and heat transfer through fibrous webs. Proc. IMechE, Part E: J. Process Mechanical Engineering, 2005, 219(E4), 357-366.

5 Fluent Manual, 2006, available from http://www. fluent.com.

6 Barth, T. J. and Jespersen, D. The design and application of upwind schemes on unstructured meshes. Technical 
Report AIAA-89-0366, AIAA 27th Aerospace Sciences Meeting, Reno, Neveda, 1989.

7 Issa, R. I. Solution of implicitly discresised fluid flow equations by operator splitting. J. Comput. Phys., 1886, 62, 40-65.

8 Prakash, C. and Voller, V. R. A fixed-grid numerical modelling for convection-diffusion mushy region phasechange problems. Int. J. Heat Mass Transfer, 1987, 30, 1709-1720.

9 Hirt, C. W. and Nichols, B. D. Volume of fluid methods for the dynamics of free boundaries. J. Comput. Phys., 1981, 39, 201-225.

\section{APPENDIX}

\section{Notation}

c specific heat $(\mathrm{J} / \mathrm{kg} \mathrm{K})$

$d_{\mathrm{f}} \quad$ diameter of fibre (m)
$E_{\text {a }} \quad$ activation energy ( $/$ mole)

$F \quad$ surface tension force $\left(\mathrm{N} / \mathrm{m}^{3}\right)$

$h, H \quad$ enthalpy $(\mathrm{J} / \mathrm{kg})$

$k_{\text {eff }} \quad$ effective thermal conductivity $\left(\mathrm{W} / \mathrm{m}^{2} \mathrm{~K}\right)$

$P \quad$ pressure $\left(\mathrm{N} / \mathrm{m}^{2}\right)$

$R \quad$ universal gas constant $(\mathrm{J} / \mathrm{kgK})$

$S \quad$ source or sink term $\left(\mathrm{N} / \mathrm{m}^{3}\right)$

$S_{\mathrm{h}} \quad$ source or sink term in the energy equation $\left(\mathrm{W} / \mathrm{m}^{3}\right)$

$t \quad$ time (s)

$T \quad$ temperature $(\mathrm{K})$

$u \quad$ velocity $(\mathrm{m} / \mathrm{s})$

$\alpha \quad$ volume fraction

$\beta \quad$ fraction of melt of sheath fibre

$\Delta h \quad$ heat of melting $(\mathrm{J} / \mathrm{kg})$

$\mu \quad$ viscosity $(\mathrm{kg} / \mathrm{ms})$

$\rho \quad$ density $\left(\mathrm{kg} / \mathrm{m}^{3}\right)$

$\sigma \quad$ surface tension force (Pa s) 
